CBIE-LACLO 2015

Anais do XXI Workshop de Informática na Escola (WIE 2015)

\title{
Um Cenário Viável para Motivar os Alunos do Ensino Fundamental para um Futuro Ingresso nos Cursos Superiores de Computação
}

\author{
Cássio D. B. Pinheiro ${ }^{1}$, Sabrina D. A. Leal ${ }^{1}$, Celson P. Lima ${ }^{1,2}$ \\ ${ }^{1}$ Instituto de Engenharia e Geociências \\ Universidade Federal do Oeste do Pará (UFOPA) - Santarém - Pará - Brasil \\ ${ }^{2}$ Massachusetts Institute of Technology (MIT) \\ Cambridge - Massachusetts - U.S.A. \\ cassio.pinheiro@ufopa.edu.br, sabrinalbarado@hotmail.com, clima@mit.edu
}

\begin{abstract}
This work focuses on areas and tools that can help raising the motivation of elementary school students to learn computer science, allowing them to better understand the area and help choosing their future careers. The vision of the project comes from the relationship between need for motivation and the Archimedes' lever, in which case the lever arm is composed of objects designed in the survey, with the foothold the fundamentals of constructivism, constructionism, Maker Movement, and Design Thinking for Educators. The proposed tools, materialized through lectures and interactive workshops are part of the package of actions to be developed in elementary school. Conclusions and future work close the paper.
\end{abstract}

Resumo. Esta pesquisa concentra-se em áreas e instrumentos que podem aumentar a motivação dos alunos do ensino fundamental para o aprendizado da ciência da computação, de maneira que estes possam conhecer melhor esta área do conhecimento e escolher melhor suas carreiras profissionais. A visão geral da proposta surgiu da relação entre necessidade de motivação e a alavanca de Arquimedes, onde neste caso o braço da alavanca é composto pelos objetos desenhados na pesquisa, tendo como ponto de apoio os fundamentos do construtivismo, construcionismo, Maker Movement e Design Thinking for Educators. Os instrumentos propostos, materializados no formato de palestras e oficinas interativas são parte integrante do pacote de ações a serem desenvolvidas nas escolas do ensino fundamental. Conclusões e trabalhos futuros encerram o artigo.

\section{Introdução}

É inegável, com base em evidências empíricas, o fato de que muitos dos ingressantes do ensino superior dos cursos de computação apresentam dificuldades no que tange a adaptação às suas carreiras acadêmicas, principalmente quanto aos requisitos necessários ao aprendizado na área escolhida. Algumas consequências que provavelmente são decorrentes desta situação estão na pesquisa de Filho et al. (2007), que apresenta dados sobre as taxas de evasão do ensino superior, os quais apontam para os cursos de Ciência da Computação, Marketing e Processamento da Informação, como os de maior evasão, com taxas (médias entre 2001 e 2005) de 32\%, 35\% e 36\% respectivamente.

Em estreita relação ao exposto no parágrafo anterior, algumas pesquisas como a de Cunha e Carrilho (2005) apontam para o fato de que a vivência no âmbito pessoal do ingressantes no ensino 


\section{CBIE-LACLO 2015}

Anais do XXI Workshop de Informática na Escola (WIE 2015)

superior pode afetar o rendimento acadêmico, tanto de forma positiva quanto negativa. Destaca-se que esta vivência, no que diz respeito a teoria construtivista de Piaget (1990), pode estar diretamente relacionada ao conjunto das experiências e das interações do processo de aprendizagem do indivíduo.

Neste contexto, o trabalho aqui apresentado discute uma proposta de um cenário de introdução à ciência da computação para crianças e jovens do ensino fundamental da rede pública e particular de ensino. Esta proposta baseia-se tanto em aspectos motivacionais como de capacitação, tendo também como diretriz principal a viabilidade de implantação em uma rede de ensino que é atualmente precária de recursos, tanto no que se refere a infraestrutura de material quanto de pessoal capacitado para a tarefa.

Importa ainda destacar que, além da precariedade de recursos da atual rede pública de ensino brasileira, existe ainda o problema frequentemente relatado por muitos professores, que é o da falta de interesse (por parte dos alunos) pela ciência básica. Uma breve análise de alguns relatórios sobre a atual conjuntura do ensino nacional facilmente sustenta a afirmativa anterior. Citando apenas dois exemplos, a avaliação internacional de estudantes feita pela $\mathrm{OCDE}^{1}$ (2012) destaca que a educação brasileira apresenta problemas nas áreas de matemática, leitura e ciências, e especialmente para as ciências, pode-se afirmar que esta deveria ser uma área de forte interesse para os alunos do ensino fundamental, por ter como base a curiosidade natural para as crianças neste nível de ensino. No entanto é observado o oposto, que é corroborado pelos dados do Censo Escolar da Educação Básica 2013, os quais mostram que na região norte do País (onde se encontra o público alvo desta pesquisa) apenas 3,84\% das escolas da Educação Básica da rede pública contam com laboratório de ciências, destacando ainda que a média nacional é de 8,19\% (INEP², 2015).

Em consequência dos fatos já citados, observa-se que muitos dos ingressantes de cursos superiores não iniciam suas atividades com o conhecimento necessário para aprender mais e melhor. Esta falta de conhecimento talvez influa negativamente na motivação para o aprendizado, justificando assim os dados apresentados no Censo da Educação Superior 2012, divulgados pelo INEP (2014), que apontam uma relação de aproximadamente 1/6 entre concludentes e ingressantes. Observa-se ainda que, com exceção dos alunos provenientes dos cursos técnicos, poucos ingressantes demonstram ter habilidades necessárias para relacionar a teoria com a prática, diminuindo assim a eficiência quanto a aplicabilidade do conteúdo repassado pelos professores.

Este artigo está estruturado da seguinte forma. Na seção 2 é destacada a visão que guia esta pesquisa, seus principais objetivos e a abordagem adotada para desenvolvê-la. A seção 3 apresenta o suporte teórico. A seção 4 discute algumas experiências e avaliações preliminares até à data. Finalmente, a seção 5 oferece uma crítica geral do trabalho, apresentando algumas conclusões e apontando caminhos futuros a serem seguidos.

\section{Visão Geral e Abordagem Metodológica}

Uma frase popularmente atribuída ao matemático e físico Arquimedes cita a possibilidade de apenas um homem mover o mundo, com uma alavanca suficientemente grande e um ponto de apoio

\footnotetext{
${ }^{1}$ A OCDE (Organização para a Cooperação e Desenvolvimento Econômico) é a responsável pelo Programa Internacional de Avaliação de Alunos - em inglês: Programme for International Student Assessment - PISA.

2 O INEP (Instituto Nacional de Estudos e Pesquisas Educacionais Anísio Teixeira) é uma organização do Governo Federal brasileiro, que tem como objetivo a promoção de estudos, pesquisas e avaliações periódicas sobre o sistema educacional brasileiro.
} 


\section{CBIE-LACLO 2015}

Anais do XXI Workshop de Informática na Escola (WIE 2015)

suficientemente firme. Os conceitos relacionados à ideia de Arquimedes dão sustentação à visão deste trabalho (figura 1), na qual ressalta-se a possibilidade de "erguer" a motivação dos alunos do ensino fundamental pela ciência da computação, usando para isso uma "alavanca" constituída de materiais e métodos específicos para a tarefa, sendo o "ponto de apoio" deste sistema, fundamentado em três conceitos, nomeadamente Construtivismo, Construcionismo e Design Thinking for Educators (DTE).

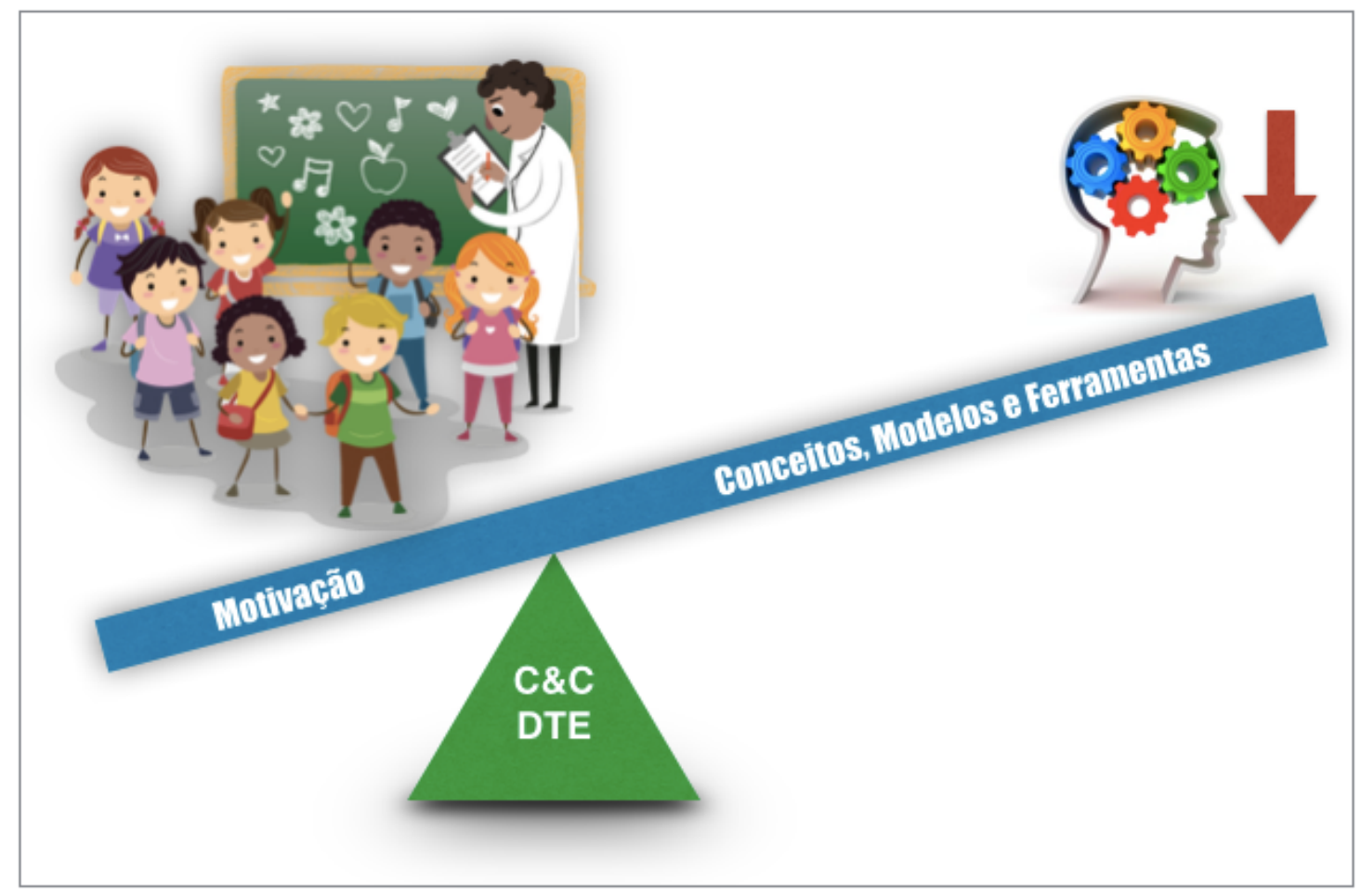

Figura 1 - Visão geral do trabalho.

Este trabalho tem como base as teorias construtivista e construcionista (C\&C) que respectivamente, implicam no desenvolvimento da inteligência dado pelas interações entre o sujeito com o meio, e na ampliação da relação entre aprendiz e computador de forma a maximizar o processo de aprendizagem (Altoé e Penati, 2005). Esta base teórica impulsionou algumas atuais iniciativas e movimentos que também dão suporte à pesquisa, nomeadamente: i) Maker Movement (MM) - variante moderna e tecnológica, baseada na premissa de que qualquer pessoa possa idealizar, construir e consertar os mais diversos objetos, bastando para isso que saiba, ou aprenda, usar as ferramentas e os equipamentos necessários à tarefa (Hatch, 2014); ii) Maker Education vertente do MM que tem especial atenção à educação, valorizando o aprendizado prático em sala de aula ou laboratório, onde o conteúdo teórico passa a ser um complemento à estas atividades (Crafts Council, 2014); e iii) Design Thinking for Educators - método concebido para ajudar os professores a compartilhar desafios diários, tendo como base quatro valores, nomeadamente a empatia, a colaboração, o otimismo e a experimentação (IDEO, 2012).

Ainda no que se refere a questão da viabilidade da implantação de uma proposta como esta aqui defendida, normalmente existe a necessidade de criar uma equipe especialmente capacitada para a tarefa, ou de capacitar os professores já em atuação com o público alvo. A criação de uma equipe gera custos elevados e a capacitação dos professores é algo que requer um tratamento mais cuidadoso, pois a relação entre salário e carga horária destes, normalmente implica na necessidade 


\section{CBIE-LACLO 2015}

Anais do XXI Workshop de Informática na Escola (WIE 2015)

de carga horária elevada e/ou da busca de fonte de renda alternativa ( $\left.\mathrm{CNTE}^{3}, 2015\right)$, reduzindo assim o tempo necessário para capacitação e/ou qualificação.

No contexto apresentado previamente, a pergunta fundamental é: Como elevar o nível de motivação e de capacitação das crianças e dos jovens para o aprendizado e a prática das ciências (especificamente na ciência da computação) de maneira que eles possam chegar ao nível superior de ensino com uma "bagagem" de conhecimento necessária ao bom aproveitamento nesta área? De se considerar ainda que esta proposta deve ser viável, com relação aos recursos materiais e humanos disponíveis.

Esta pesquisa busca respostas à pergunta colocada no parágrafo anterior, trabalhando sobre um cenário de capacitação que envolva motivação, baixo custo, material auto-explicativo e facilidade de uso. Na mesma direção de iniciativas já em evidência como a Khan Academy ${ }^{4}$ e a Hour of Code ${ }^{5}$; esta proposta pretende usar fortemente os recursos tecnológicos, com base nas práticas definidas na teorias construcionista de Papert (1980), para definir materiais e métodos necessários à criação conhecimento através da interação do aluno com ferramentas tecnológicas (e.g. o computador).

Este trabalho explora a aplicação da metodologia científica conhecida como Pesquisa-Ação (PA) para explorar o cenário proposto. A PA trabalha com uma base empírica concebida para associar a ação com a solução de um problema, onde ambos (pesquisador e participantes) estão envolvidos de modo colaborativo e participativo, assim propiciando a aquisição de conhecimento teórico (Mills, 2007). Observa-se ainda que este conhecimento pode ser tratado através de conceitos oriundos da área de Gestão do Conhecimento, pois estes permitem a coordenação de pessoas, tecnologias, processos e estruturas, os quais tem como principal objetivo a agregação de valor através da reutilização do conhecimento (Dalkir, 2005).

O público-alvo dos experimentos que sustentam esta proposta é prioritariamente formado por alunos e por professores do ensino fundamental, onde fatores relacionados a pré-disposição ao aprendizado, levaram a escolha de turmas do final do ensino fundamental menor, com idades variando entre 10 e 12 anos. Atualmente, algumas escolas próximas a área central da cidade de Santarém, estado do Pará (com aproximadamente 300,000 habitantes), estão sendo selecionadas, onde o critério de seleção está pautado na visão inovadora da administração da instituição selecionada e na receptividade dos alunos à ideia.

A área de conhecimento inicialmente selecionada foi a computação, pois além de sua prática ser notadamente motivadora, existem diversos projetos, ligados a grandes centros de ensino, relacionados a esta iniciativa, nomeadamente: (i) a plataforma de programação visual Scratch, que conta como uma estratégia para tornar a programação atrativa e acessível a todos (Resnick et al, 2009); e (ii) o movimento global Hour of Code, que disponibiliza no seu website muitos tutoriais interativos com conceitos básicos sobre introdução à ciência da computação, assim como seus

3 A CNTE (Confederação Nacional dos Trabalhadores em Educação) é uma organização não governamental que congrega as várias federações setoriais da educação numa mesma entidade nacional.

4 A Khan Academy (http://www.khanacademy.org) é uma ONG educacional que objetiva proporcionar educação de alta qualidade para qualquer um, em qualquer lugar, oferecendo uma coleção grátis de vídeos sobre as mais diversas disciplinas e áreas.

${ }^{5}$ A Hour of Code é uma iniciativa da CODE (http://code.org) que provê recursos diversos para desmistificar o código computacional e mostrar que qualquer um pode aprender as noções básicas da ciência da computação. 
respectivos materiais de apoio para dar suporte aos parceiros da proposta, fazendo com que qualquer pessoa, em qualquer lugar, possa organizar um evento (Hour of Code, 2014).

\section{Suporte Teórico}

A presente pesquisa pretende fortalecer as ações relacionadas ao aprendizado da ciência da computação nas escolas de ensino fundamental. Neste contexto, esta parte do trabalho discorre sobre as diretrizes metodológicas baseadas nas teorias $\mathrm{C} \& \mathrm{C}$, as quais atualmente fortalecem diversas iniciativas educacionais, assim como dão sustentação teórica a esta pesquisa.

\subsection{Construtivismo e Construcionismo}

Para o Construtivismo o indivíduo desenvolve suas representações de mundo e não recebe passivamente impressões causadas pelos objetos, sendo assim o sujeito proativo. Desta forma, "o desenvolvimento mental aparecerá, em sua organização progressiva como uma adaptação sempre mais precisa da realidade" (Piaget, 1964, p.16). A teoria construtivista considera que um erro corrigido pelo próprio aprendiz pode ser mais produtivo do que um acerto imediato, pois comparando hipóteses e refletindo sobre a ação é que se obtêm novas ideias e novos conhecimento (Piaget, 1990).

A teoria Construcionista busca meios de aprendizagem que valorizem a construção das estruturas cognitivas do sujeito a partir de suas ações. Segundo Papert, a teoria é definida pela construção do conhecimento por meio do computador, onde este torna-se um elemento de “interação que propicia o desenvolvimento da autonomia do aluno, não direcionando a sua ação, mas auxiliando-o na construção de conhecimentos de distintas áreas do saber" (Almeida, 1999, p. 29).

Desta maneira, procedimentos como a experimentação, a pesquisa em grupo e o estimulo à dúvida, permitem ao aluno participar do seu aprendizado, estabelecendo os atributos dos objetos e assim construindo as características do seu universo de aprendizado. Também pode ser observado que ambas as teorias enfatizam a importância do erro como um caminho na busca do aprendizado.

\subsection{Maker Movement (Movimento do Fazedor)}

O MM está se definindo como um novo mantra para pessoas que acreditam que aprender observando já não é mais o suficiente e estão partindo para o fazer. Este fazer não está relacionado apenas aos elementos necessários para seguir um procedimento em um manual ou "receita de bolo", mas foca-se na criação de uma ideia e na busca do conhecimento e dos instrumentos necessários para concretizá-la. Com base na cultura conhecida como Do-It-Yourself, o Movimento do Fazedor é sustentado por três pilares interligados em ciclo, a saber: i) Informação e recursos acessíveis em comunidades online, ii) a democratização de ferramentas de produção e o iii) desenvolvimento de ideias através de novas ferramentas digitais (Anderson, 2011).

Anderson (2011) defende ainda que se estabeleceu uma cultura de que as pessoas devem compartilhar seus projetos e suas soluções, colaborando com outras pessoas e assim sustentar o crescimento das comunidades online, de forma a tornar as ideias tangíveis, com menor necessidade de esforço e de tempo para desenvolvê-las.

\subsection{MM na Educação}

Observa-se que o MM, diferentemente de apenas uma proposta em sentido contrário ao da teoria por si só, ocupa-se principalmente em redefinir o sentido do participar, democratizar a experiência e falhar. Isso pode ser ressaltado em comentários de alguns dos atuais ícones da inovação e da ciência, como o educador britânico Sir Ken Robinson, Tim Brown (IDEO), Joi Ito (MIT Media 


\section{CBIE-LACLO 2015}

Anais do XXI Workshop de Informática na Escola (WIE 2015)

Lab) e o astrofísico Neil Tysson, que estudam e criticam a atual forma de aprendizado, onde a teoria vem antes da prática, destacando que o aprender fazendo pode minimizar o fator medo e principalmente redefinir o que é errado (Sakamoto, 2014).

Observa também que as mudanças na educação devem ser propostas em ambientes educacionais inovadores, destacando que as barreiras que têm sufocado a escola devem ser transpostas: (i) a de disciplina, para que os alunos possam aprender por projetos; a de tempo, para que não sejam obrigados a dedicar apenas uma hora a alguma atividade; (ii) a de idade, para que colegas de séries distintas possam aprender uns com os outros; e (iii) a dos muros da escola, destacando que é necessário fazer com que o aprendizado dure o dia inteiro, assim como deve-se provar que as atividades executadas fora da escola podem influenciar no que é feito dentro - e viceversa (Resnick et al, 2005) (Schmidt, Resnick \& Rusk, 2015).

\subsection{Design Thinking for Educators}

São muitos os problemas que a educação enfrenta e o Design Thinking, por definição é uma nova maneira de pensar e abordar este problemas, concentrando esforços no modelo de pensamento das pessoas. Segundo Stuber (2012) existem diversas abordagens desta metodologia, no entanto, a visão para educadores, DTE, está centrada em transformar os problemas em oportunidades.

De maneira geral, o DTE é definido através da visão de que os professores podem fazer a diferença através de inovações relevantes, que criem um impacto positivo, transformando desafios em oportunidades (IDEO, 2012). Desta forma apresenta características específicas, a saber: i) centrado no ser humano - inicia a partir da empatia e compreensão das necessidades e motivações do público alvo; ii) colaboração - beneficia o processo de desenvolvimento pela observação de várias perspectivas; iii) otimismo - tem como base a crença de que todos podem inovar e criar mudanças, não importando a complexidade do problema; e iv) experimentação - com foco no aprender fazendo, aceita a falha como um caminho para o aprendizado.

\section{Experimentos e Avaliações Preliminares}

Esta parte do artigo introduz o conjunto básico das diretrizes de implementação dos experimentos, assim como suas formas de aplicação e de uso. Após isso serão apresentados dois dos sete eventos que fazem parte deste experimento (até o momento), destacando as principais características, os processos de avaliação e a importância destes para contexto geral da pesquisa.

\subsection{Diretrizes Gerais do Experimento}

Em consonância como as diretrizes gerais da PA (que definem fases recorrentes para reflexão, planejamento, ação e observação (Mills, 2007)), o método usado na execução deste trabalho tem como base os procedimentos experimentais adotados pelo DTE, os quais definem em suas premissas que, devido a diversidade de necessidades dos alunos, o trabalho do professor nunca pode ser considerado acabado ou resolvido, estando sempre em andamento (IDEO, 2012). Desta maneira, o trabalho aqui proposto foca-se tanto na implementação como na avaliação incremental de ações práticas relacionadas à motivação dos alunos, quanto ao aprendizado da ciência da computação.

No que tange às experiências prévias envolvendo a visão geral sustentando este trabalho, podem ser destacadas as atividades iniciadas no segundo semestre de 2013 , em sala de aula na Universidade Federal do Oeste do Pará, nas disciplinas de eletricidade e eletrônica do curso de Ciências da Computação. No modelo de atividades adotado para estas disciplinas, os preceitos do MM e do DTE foram implementados em todas as aulas, de forma que a teoria foi sempre precedida por um breve experimento prático, que além de aguçar a curiosidade do aluno, o inseriu de forma efetiva no universo do conteúdo teórico programado para a aula. 


\section{CBIE-LACLO 2015}

Anais do XXI Workshop de Informática na Escola (WIE 2015)

Ao final de cada aula os alunos são constantemente incentivados e desafiados a contribuir de forma colaborativa com idéias para novos experimentos, os quais são concebidos para serem de fácil compreensão e implementação, sendo assim viáveis para uso em outros níveis de ensino, mais especificamente para o ensino fundamental. Os experimentos definidos nas aulas são tratados como produtos, e deste modo documentados, catalogados e disponibilizados para os mais diversos usos.

Com os produtos devidamente preparados, estes podem ser encaminhados ao público alvo nas seguintes modalidades: i) Palestras e Oficinas - organizadas como eventos independentes ou inseridas em eventos maiores, estas tem caráter informativo e prático, voltadas principalmente para divulgar a ideia geral do projeto; ii) Web Site - este atua principalmente como repositório de informações sobre os produtos desenvolvidos. Seguindo os preceitos da Gestão de Conhecimento, este repositório objetiva organizar informações e conhecimentos, identificando-os e catalogando-os, de maneira que possam ser facilmente recuperados (Davenport e Prusak 1998); e iii) Tutoriais Interativos - em fase de implantação, objetivam minimizar o problema da falta de tempo para capacitação e preparação dos professores, quanto às atividades práticas. Estes tutoriais tem como principal alvo a representação de conhecimento e conteúdos de maneira simples e auto-explicativa, onde os professores que conduzirão a atividade possam até aprender juntamente com os alunos.

Os tipos de experimentos apresentados também podem envolver parcerias que vão desde eventos locais organizados pela própria universidade, assim como por outras organizações (como entidades comunitárias e escolas da rede pública de ensino). Instituições privadas também devem selecionadas como alvo do experimento, principalmente por se destacarem dentre as instituições de ensino local e assim poderem ser tratadas como instituições de referência. Usando da experiência pregressa, assim como de produtos desenvolvidos pelos próprios alunos da universidade, incluindose nestes os trabalhos de estágio e de conclusão de curso, este projeto pôde implementar alguns experimentos motivacionais, apresentados a seguir.

\subsection{Algumas Instâncias do Experimento}

A partir do segundo semestre de 2014 a proposta motivacional foi iniciada com alunos de 10 a 12 anos da escola da rede pública de ensino fundamental Professora Sofia Imbiriba, localizada na periferia de Santarém. Esta iniciativa ocorreu em sua maior parte de acordo com as especificações da escola, que optou pelo processo muito comum na região, no qual um dos membros da equipe de projeto (neste caso uma aluna concluinte do curso de Sistemas de Informação da UFOPA), sempre acompanhado de um professor da escola, conduziu o experimento.

Esta atividade é rotulada de Oficina Interativa (num total de quatro oficinas de duas horas cada) sobre programação visual no ambiente Scratch, que teve como objetivo principal o desenvolvimento gradativo do raciocínio lógico e da lógica matemática, através das interações com o ambiente de programação Scratch.

O processo de avaliação da atividade observou três aspectos, a saber: i) a visão da professora foi expressada através de entrevista, onde esta ressaltou o interesse dos alunos pela ferramenta e pelo formato das atividades, destacando ainda o caráter inovador da mesma; ii) o questionário de avaliação preenchido pelos alunos destacou a facilidade de compreensão do material, assim como as possibilidades de relação do conteúdo trabalhado em outras atividades curriculares; e iii) no relatório final da aluna responsável pelo evento destaca-se a dificuldade inicial que esta teve em fazer com que os alunos compreendessem os enunciados das atividades práticas, $\mathrm{o}$ que já não acontecia no final do processo, pois rapidamente os alunos se habituaram, tanto ao paradigma que envolve a teoria na prática, quanto ao formato e especificidades do material usado. 


\section{CBIE-LACLO 2015}

Anais do XXI Workshop de Informática na Escola (WIE 2015)

Esta instância do experimento, mesmo ainda não estando totalmente de acordo com as diretrizes determinadas, teve fundamental importância para a pesquisa, pois através dela muitos dos problemas aqui expostos foram vivenciados. Desta maneira, os acertos e principalmente os erros cometidos durante a atividade, foram fundamentais para validação da proposta quanto a receptividade e dificuldade para adaptação dos professores para as características de interatividade e funcionalidade do material usado, permitindo assim a definição mais eficiente das melhorias especificadas para os eventos subsequentes.

Em dezembro de 2014 ocorreu a segunda instância em destaque, que foi a Oficina de Arduino Usando Scratch - inserida na I Semana de Tecnologias Educacionais da UFOPA. A escolha da temática se deu pelo atual sucesso dos dispositivos para desenvolvimento de aplicações embarcadas como Arduino ${ }^{6}$, Galileo ${ }^{7}$ e outros, que estão trazendo para o público em geral o forte relacionamento entre a computação e a eletrônica, que anteriormente era quase de exclusividade de engenheiros. Com público-alvo variado, contando com alunos de escolas do ensino fundamental e professores universitários, o evento apresentou (através de oficina interativa) uma noção geral do uso do Arduino através da linguagem de programação Scratch.

Com duas horas de duração, a oficina foi totalmente conduzida através da execução de atividades com níveis de dificuldade crescente, iniciando com a simples ativação de um LED (Figura 2), passando para o piscar alternado de dois LEDs e finalizando com o desenvolvimento de um semáforo. Contando com um material que implementava passo-a-passo as atividades (Figura 3), a oficina em questão foi facilmente conduzida por dois alunos do quarto semestre do curso de Ciência da Computação da UFOPA.

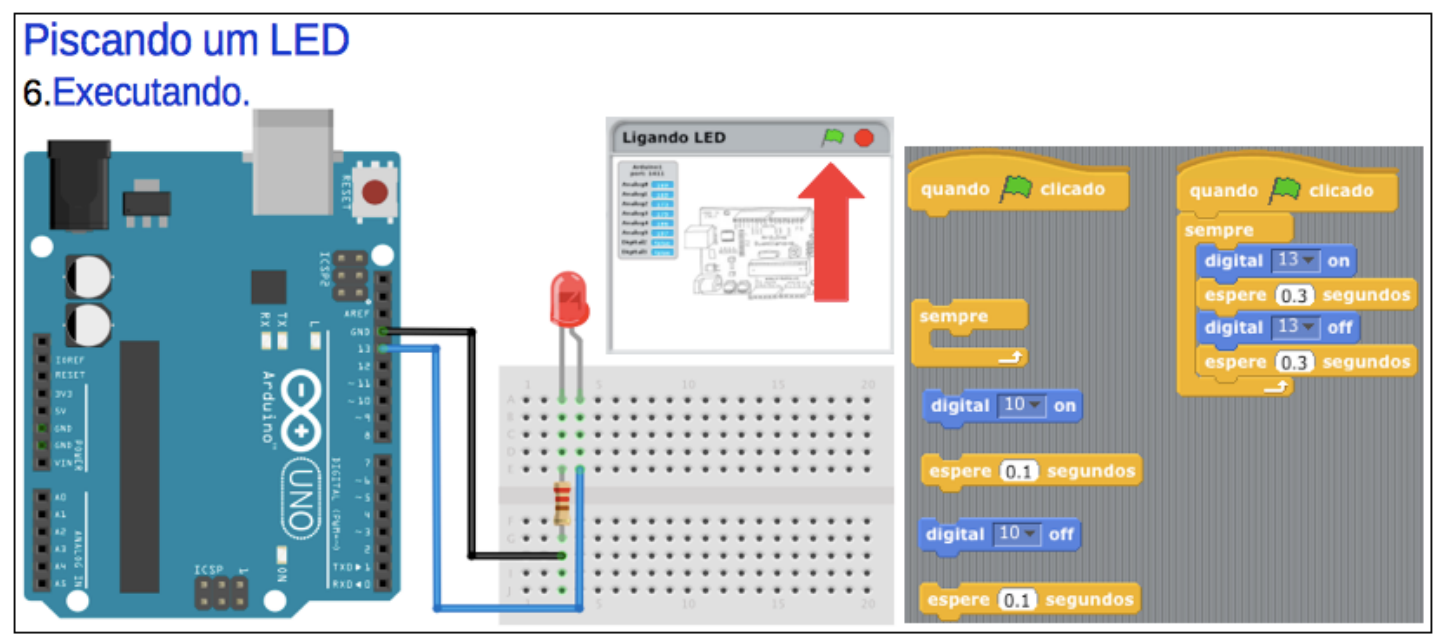

Figura 2 - Produto usado na Oficina Interativa.

Como o evento em que a oficina foi inserida não contava com um procedimento formal de avaliação, ao final da atividade os professores presentes e alguns alunos foram questionados quanto a validade e as características da oficina. De modo geral, destacou-se a facilidade do desenvolvimento de produtos em nível progressivo de dificuldade e a forma interativa de execução destas. Em particular, os alunos destacaram a maneira prática de apresentação do conteúdo teórico e os professores apontaram para as características de interatividade e facilidade de uso do material.

\footnotetext{
6 Arduino (http://www.arduino.cc) é uma plataforma de hardware livre usada para o aprendizado e a prototipagem de sistemas embarcados.

${ }^{7}$ Intel Galileo (http://www.intel.com) é um hardware de desenvolvimento com características semelhantes ao Arduino, baseado na arquitetura Intel x86 e projetado para as comunidades de Makers e de educadores.
} 
CBIE-LACLO 2015

Anais do XXI Workshop de Informática na Escola (WIE 2015)

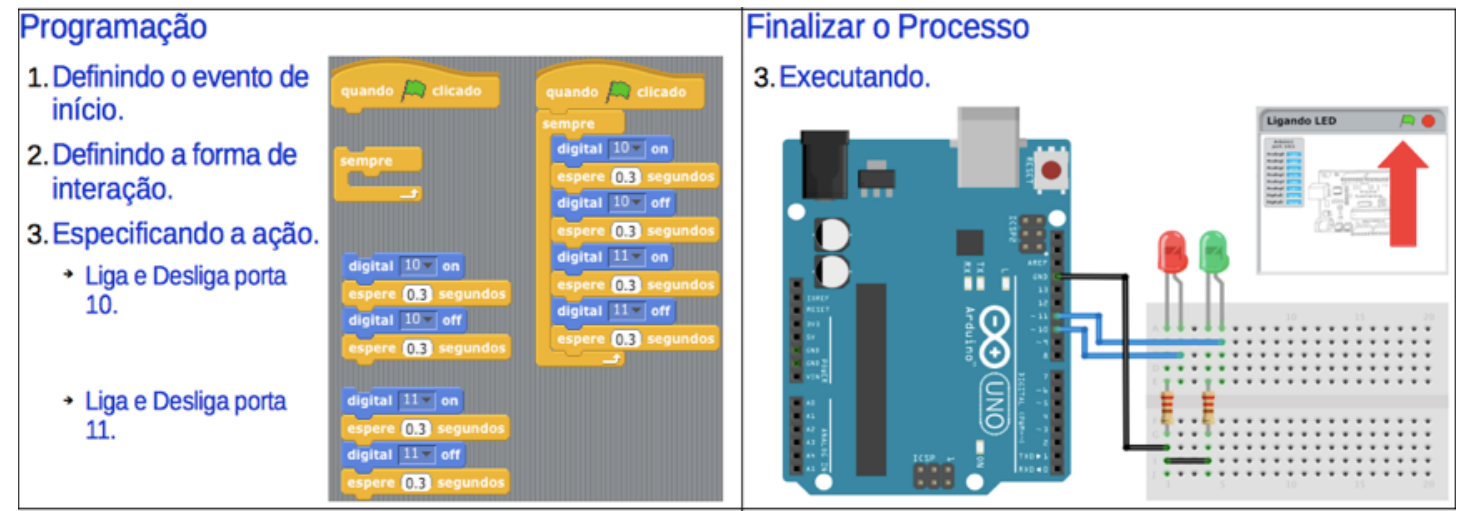

Figura 3 - Desenvolvimento passo-a-passo dos produtos.

\section{Discussões e Trabalhos Futuros}

Mesmo que o MM não tenha necessariamente surgido a partir das teorias $\mathrm{C} \& \mathrm{C}$, é visível a relação entre eles. No referido aos produtos desta relação, quando em parceria com métodos de trabalho como PA e DTE, podem gerar frutos de grande valia para o apoio às atividades do ensino fundamental, que tanto carece de recursos e de motivação, como demostrado através da descrição dos problemas, das ações implementadas e dos resultados descritos neste artigo.

É importante destacar na metodologia selecionada que a parceria entre os fundamentos da PA e da Gestão do Conhecimento permitiram o mapeamento, a identificação e a externalização dos tipos e fontes de conhecimento especificadas no âmbito da universidade. De se referir ainda que os estudantes de graduação partilham muitas variáveis com crianças em escolas do ensino fundamental, já que estes faziam parte dos experimentos iniciais e foram fundamentais na identificação e na determinação da nova representação dos tipos de conhecimento selecionados.

Iniciativas como a Hora do Código foram fundamentais para o desenvolvimento dos objetos de aprendizagem usados neste projeto, mas o trabalho nestes só será encerrado quando o nível de compreensão e usabilidade for suficiente para que o público-alvo os usem de forma autônoma. Para que isso seja possível cada objeto desenvolvido deverá contar com um conjunto de metainformações que permitam estas facilidades, sendo o desenvolvimento destas metainformações o trabalho atual da equipe.

É necessário destacar ainda que, mesmo que sete experimentos formais já tenham sido catalogados, este trabalho ainda está em seu estágio inicial e certamente necessita ser enriquecido com critérios adicionais de avaliação e validação. Mesmo assim, os resultados preliminares são animadores, pois é visível a aceitação do método por parte dos professores e a forma expontânea como os alunos se empenham para entender e executar as tarefas.

\section{Referências}

Almeida, M. (1999) "O aprender e a informática: a arte do possível na formação do professor". In: Cadernos Informática para a mudança em educação. MEC/SEED/PROINFO.

Altoé, A. e Penati, M. (2005) "O Construtivismo e o Construcionismo Fundamentando a Ação Docente”. In: Educação e Novas Tecnologias. Eduem.

Anderson, C. (2011) "Makers: The New Industrial Revolution". New York: Crow Business.

CNTE. (2015) "Relatório De Pesquisa Sobre a Situação dos Trabalhadores(as) da Educação Básica". In: Retrato da Escola 3. Confederação Nacional dos Trabalhadores em Educação. http:// 


\section{CBIE-LACLO 2015}

Anais do XXI Workshop de Informática na Escola (WIE 2015)

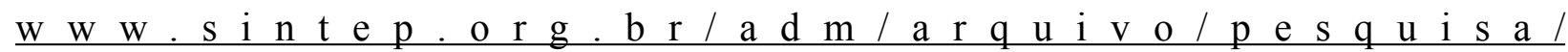
$1282009 \quad 17 \quad 51 \_10$ pesquisa_retrato_da_escola_3.pdf, Janeiro.

Crafts Council. (2014) "Our Future Is In The Making: An Education Manifesto for Craft and Making". Crafts Council.

Cunha, M., Carrilho, M. (2005) "O Processo de Adaptação ao Ensino Superior e o Rendimento Acadêmico". In: Psicologia Escolar e Educacional, v. 9, n 2.

Dalkir, K. (2005) "Knowledge management in theory and practice". Elsevier ButterworthHeinemann.

Davenport, T. e Prusak, L. (1998) "Working Knowledge: How Organizations Manage What They Know". Harvard Business School Press.

Filho. R., Motejunas, P., Hipólito, O. e Lobo, M. (2007) “A Evasão no Ensino Superior Brasileiro”, In: Cadernos de Pesquisa, v. 37, n. 132.

Hatch, M. (2014) "The Maker Movement Manifesto". McGraw-Hill Education.

Hour of Code (2014) "Hour of Code: Perguntas Frequentes". Hour of Code. http://hourofcode.com/ br, Fevereiro.

IDEO. (2012) "Design Thinking for Educators Toolkit". 2 ed. IDEO.

INEP. (2014) "Censo da educação superior 2012: Resumo técnico". Instituto Nacional de Estudos e Pesquisas Educacionais Anísio Teixeira.

INEP. (2015) "Censo Escolar 2013". Instituto Nacional de Estudos e Pesquisas Educacionais Anísio Teixeira. http://portal.inep.gov.br/basica-censo, Janeiro.

Mills, G. (2007) "Action research: a guide for the teacher researcher". Pearson Education.

OCDE. (2012) "Programme for International Student Assessment: Results from PISA 2012". Organisation de Coopération et de Développement Economiques.

Papert, S. (1980) "Mindstorms - Children, Computers and Powerful Ideas". Basic Books.

Piaget, J. (1964) "Seis estudos de psicologia". Forense: Rio de Janeiro.

Piaget, J. (1990) "Epistemologia Genética". Martins Fontes: São Paulo.

Resnick, M., Maloney, J., Monroy-Hernández, A., Rusk, N., Eastmond, E., Brennan, K., Millner, A., Rosenbaum, E., Silver, J., Silverman, B. e Kafai, Y. (2009) "Scratch: Programming for All". In: Communications of the ACM, v. 52, n 11.

Resnick, M., Myers, B., Nakakoji, K., Shneiderman, B., Pausch, R., Selker, T., \& Eisenberg, M. (2005). Design Principles for Tools to Support Creative Thinking. National Science Foundation workshop on Creativity Support Tools.

Sakamoto, G. (2014) "Maker Movement". http://exame.abril.com.br/rede-de-blogs/austin-direct/ 2014/03/13/maker-movement, Julho.

Schmidt, P., Resnick, M., \& Rusk, N. (2015). "Learning Creative Learning: How we tinkered with MOOCs". P2PU Reports. http://reports.p2pu.org/learning-creative-learning/, Janeiro.

Stuber. E. (2012) "Inovação pelo Design: uma proposta para o processo de inovação através de wokshops utilizando o design thinking e o design estratégico". Dissertação de Mestrado Universidade do Vale do Rio dos Sinos: Porto Alegre. 